\title{
Nitrogen and Hydrogen Gas Adsorption Properties of Microporous Ruthenium Coordination Polymers
}

\author{
Yuhei Miyazaki, ${ }^{1}$ Yusuke Kataoka, ${ }^{2}$ Wasuke Mori ${ }^{1,}$ *
}

a) Department of Chemistry, Faculty of Science, Kanagawa University, 2946, Tsuchiya, Hiratsuka, Kanagawa, 259-1293.

Fax: 81-463-58-9684, E-mail: wmori@kanagawa-u.ac.jp

b) Department of Chemistry, Graduate School of Science, Osaka University, 1-1, Machikaneyama, Toyonaka, Osaka, $560-0043$. Fax: 81-6-6850-5550

We investigated nitrogen and hydrogen gas adsorption properties of microporous ruthenium coordination polymers constructed from $\mathrm{Ru}^{\mathrm{II} / \mathrm{III}}{ }_{2}$ paddle wheel motif and dicarboxylic organic linkers such as terepthalic acid, fumaric acid, muconic acid and succinic acid. In nitrogen gas adsorption measurements, we calculated adsorption parameters such as surface area (Langmuir), pore volume and pore diameter. The relation between adsorption parameters and maximum amount of hydrogen uptake was discussed.

Key words: Microporous coordination polymer, Gas adsorption, mix-valence Ru complexes

\section{Introduction}

Microporous metal coordination polymers called metal organic frameworks (MOFs) have attracted a great deal of attention in the past decade because of their captivating structural diversities and intriguing potential applications, such as gas storage, separation, catalysis, and chemical sensing. The properties of gas-adsorption into MOFs were first found in the $\left[\mathrm{Cu}_{2}(\mathrm{TP})_{2}\right]_{\mathrm{n}}(\mathrm{TP}=$ terepthalic acid) by Mori and his co-workers[1]. Nowadays, many scientists have synthesized novel nano-porous crystals and their properties [2-4]. As known widely, $\mathrm{Cu}$ or $\mathrm{Zn}$ ions are useful as building blocks of MOFs. However, in the viewpoint of catalysis, their metal ions could not expect high catalytic performance. Therefore, in our laboratory, various metal coordination polymers incorporated with dinuclear paddlewheel motif such as $\mathrm{Ru}_{2}, \mathrm{Rh}_{2}$ ions were also reported [5-11]. These materials were focused on not only gas-adsorption but also heterogeneous catalyst. For example, $\quad\left[\mathrm{Ru}_{2}(\mathrm{TP})_{2}\right]_{\mathrm{n}}$ was very useful for hydrogeneration catalyst [5]. $\quad\left[\mathrm{Rh}_{2}(\mathrm{TP})_{2}\right]_{\mathrm{n}}$ and $\left[\mathrm{Rh}_{2}(\mathrm{FMA})_{2}\right]_{\mathrm{n}} \quad\left(\mathrm{FMA}=\right.$ fumarate) and $\left[\mathrm{Rh}_{2}(\mathrm{MTCPP})\right]_{\mathrm{n}}$ $\left(\mathrm{M}=\mathrm{H}_{2}, \mathrm{Cu}, \mathrm{Pd}\right.$ and $\mathrm{Ni} ; \mathrm{H}_{2} \mathrm{TCPP}=4,4^{\prime}, 4^{\prime \prime}, 4^{\prime \prime},-(21 \mathrm{H}$, 23H-porphine-5,10,15,20-tetrayl) tetrakis benzoic acid) complexes have exhibited high catalytic activities for $\mathrm{H}-\mathrm{D}$ exchange and hydrogenation of olefin (ethylene, propene, and butene) at $200 \mathrm{~K}$ [6-7]. $\left[\mathrm{Ru}_{2}\left(\mathrm{H}_{2} \mathrm{TCPP}\right) \mathrm{BF}_{4}\right]_{\mathrm{n}}$ showed outstanding selectivity ( $>99 \%$ ) for oxidation of primary aliphatic alcohols with air without any additives at room temperature[8]. Recently, we have been also reported the photochemical hydrogen production from water using these microporous ruthenium and rhodium coordination polymers [9-10]. Therefore, our reported ruthenium or rhodium coordination polymers are utility materials for heterogeneous catalyst and the development of more effective catalyst is desirable.

As above described, microporous ruthenium coordination polymers were especially promising materials for heterogeneous catalyst. Interestingly, the valence of dinuclear $\mathrm{Ru}_{2}$ motifs took the mix-valence of
$\mathrm{Ru}^{\mathrm{II}} / \mathrm{Ru}^{\mathrm{III}}$ species. Therefore, according to choice of the counter-ion, several differential coordination polymers are obtained. As one example, we reported the microporos materials $\left[\mathrm{Ru}_{2}(\mathrm{~L})_{2} \mathrm{Cl}\right]_{\mathrm{n}} \quad(\mathrm{L}=$ dicarboxylate) which have a three-dimensional jungle-gym-type structure, in which a two-dimensional square grid sheet composed of a dinuclear ruthenium (II, III) paddlewheel motif with a dicarboxylate organic linkers are bridged by halogen counterions to extend the two-dimensional structure into a threedimensional structure [11]. (See Figure 1.)

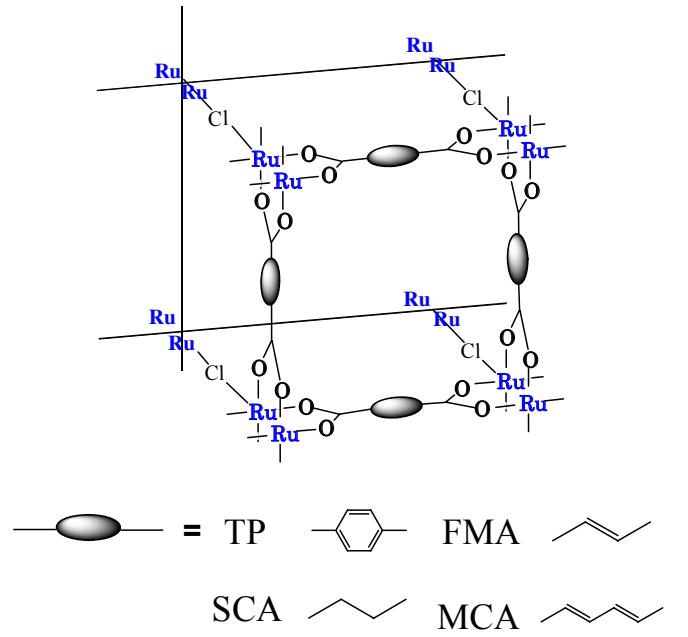

Figure 1. Molecular structure of microporous ruthenium coordination polymers.

In order to develop the coordination polymer catalysts, it is important that adsorption properties of coordination polymers are closely investigated. In 2005, we reported the gas-adsorption properties and BET surface area of $\left[\mathrm{Ru}_{2}(\mathrm{~L})_{2} \mathrm{Cl}\right]_{\mathrm{n}}$ [8]. Recently, Silva et.al. reported gas adsorption properties and adsorption parameters such as BET surface area, pore volume and pore diameters of same complexes [12]. However, 
Silva's reported parameters are obviously incorrect, (1) micropore-filling of adsorption isotherm was not found, (2) pore diameter was obviously too large, (3) maximum amount of $\mathrm{N}_{2}$ molecule was also too large. Therefore, in order to develop the ruthenium coordination polymers, it is required to correct the incorrect data to reliable data.

In this paper, we describe the gas adsorption properties of four microporous ruthenium coordination polymers $\left[\mathrm{Ru}_{2}(\mathrm{~L})_{2} \mathrm{Cl}\right]_{\mathrm{n}}$, which were constructed from $\mathrm{Ru}^{\mathrm{II} / \mathrm{III}} 2$ paddle wheel motif and four dicarboxylate ligands, i.e. terepthalic acid $\left(\mathrm{H}_{2} \mathrm{TP}\right)$, fumaric acid $\left(\mathrm{H}_{2}\right.$ FMA $)$, muconic acid $\left(\mathrm{H}_{2} \mathrm{MCA}\right)$ and succinic acid $\left(\mathrm{H}_{2} \mathrm{SCA}\right)$.

\section{Results and Discussion}

$\mathrm{Ru}^{\mathrm{II} / \mathrm{III}}{ }_{2}$ motifs were prepared by a procedure reported previously for $\left[\mathrm{Ru}_{2}(\mathrm{~L})_{2} \mathrm{Cl}\right]_{\mathrm{n}} \quad[11] . \quad \mathrm{N}_{2}$ or $\mathrm{H}_{2}$ gas adsorption measurements were conducted by Shimazu ASAP 2010 volumetric adsorption analyzer at the $77.35 \mathrm{~K}$ and $760 \mathrm{mmHg}$ after vacuuming sample for eliminating solvent molecular in the pore. As shown Figure 2, in these complexes, $\mathrm{N}_{2}$ gas isotherms show micro-pore filling at low pressure and the amount of $\mathrm{N}_{2}$ gas adsorbed is increased slowly. At near the high pressure $(760 \mathrm{mmHg})$, large rise of $\mathrm{N}_{2}$ gas adsorption depended on void space between particles is observed. These adsorption isotherms are typically a type I (Langmuir type) in the IUPAC classification. Langmuir surface area of $\left[\mathrm{Ru}_{2}(\mathrm{TP})_{2} \mathrm{Cl}\right]_{\mathrm{n}}, \quad\left[\mathrm{Ru}_{2}(\mathrm{FMA})_{2} \mathrm{Cl}\right]_{\mathrm{n}}$, $\left[\mathrm{Ru}_{2}(\mathrm{MCA})_{2} \mathrm{Cl}\right]_{\mathrm{n}}$ and $\left[\mathrm{Ru}_{2}(\mathrm{SCA})_{2} \mathrm{Cl}\right]$ calculated from these isotherms is $525.5 \mathrm{~m}^{2} / \mathrm{g}, 470.3 \mathrm{~m}^{2} / \mathrm{g}, 645.4 \mathrm{~m}^{2} / \mathrm{g}$ and $500.1 \mathrm{~m}^{2} / \mathrm{g}$, respectively. The surface area of $\mathrm{Ru}^{\mathrm{II} / I I}$ motifs is good agreement with the order of the length of ligand $\left(\mathrm{H}_{2} \mathrm{FMA}<\mathrm{H}_{2} \mathrm{SCA}<\mathrm{H}_{2} \mathrm{TP}<\mathrm{H}_{2} \mathrm{MCA}\right)$. Moreover, the maximum amounts of $\mathrm{N}_{2}$ gas adsorbed are as followed: $170.1 \mathrm{~cm}^{3} / \mathrm{g}$ by $\left[\mathrm{Ru}_{2}(\mathrm{TP})_{2} \mathrm{Cl}\right]_{\mathrm{n}}, 171.0 \mathrm{~cm}^{3} / \mathrm{g}$ by $\left[\mathrm{Ru}_{2}(\mathrm{FMA})_{2} \mathrm{Cl}\right]_{\mathrm{n}}, \quad 221.9 \mathrm{~cm}^{3} / \mathrm{g}$ by $\left[\mathrm{Ru}_{2}(\mathrm{MCA})_{2} \mathrm{Cl}\right]_{\mathrm{n}}$, $217.4 \mathrm{~cm}^{3} / \mathrm{g}$ by $\left[\mathrm{Ru}_{2}(\mathrm{SCA})_{2} \mathrm{Cl}\right]_{\mathrm{n}}$, respectively. Coordination polymers constructed from straight chain organic linker sometimes form interpenetrated frameworks. As an example of such interpenetrated frameworks, $\mathrm{Cu}_{2}^{\mathrm{II} / \mathrm{II}}$ paddle wheel type coordination polymers selected $\mathrm{H}_{2} \mathrm{FMA}$ ligand were reported previously [13]. Therefore, these $\mathrm{Ru}^{\mathrm{II} / \mathrm{III}}{ }_{2}$ motifs are much useful for the construction of microporous coordination polymers maintained high surface area. The pore diameter and pore volume are calculated by Harvous- Kawazoe method [14]. The pore diameter of $\left[\mathrm{Ru}_{2}(\mathrm{TP})_{2} \mathrm{Cl}\right]_{\mathrm{n}}, \quad\left[\mathrm{Ru}_{2}(\mathrm{FMA})_{2} \mathrm{Cl}\right]_{\mathrm{n}}, \quad\left[\mathrm{Ru}_{2}(\mathrm{MCA})_{2} \mathrm{Cl}\right]_{\mathrm{n}}$ and $\left[\mathrm{Ru}_{2}(\mathrm{SCA})_{2} \mathrm{Cl}\right]$ is $4.9 \AA, 4.8 \AA, 4.6 \AA$ and $4.8 \AA$, respectively. The pore volume of $\left[\mathrm{Ru}_{2}(\mathrm{TP})_{2} \mathrm{Cl}\right]_{\mathrm{n}}$, $\left[\mathrm{Ru}_{2}(\mathrm{FMA})_{2} \mathrm{Cl}\right]_{\mathrm{n}},\left[\mathrm{Ru}_{2}(\mathrm{MCA})_{2} \mathrm{Cl}\right]_{\mathrm{n}}$ and $\left[\mathrm{Ru}_{2}(\mathrm{SCA})_{2} \mathrm{Cl}\right]$ is also good agreement with the order of surface area and is $0.265 \mathrm{~cm}^{3} / \mathrm{g}, 0.151 \mathrm{~cm}^{3} / \mathrm{g}, 0.265 \mathrm{~cm}^{3} / \mathrm{g}$ and $0.150 \mathrm{~cm}^{3} / \mathrm{g}$, respectively.

$\mathrm{H}_{2}$ gas adsorption isotherms are shown in Figure 3. The amount of $\mathrm{H}_{2}$ gas adsorbed is $0.70 \mathrm{wt} \%$ by $\left[\mathrm{Ru}_{2}(\mathrm{TP})_{2} \mathrm{Cl}\right]_{\mathrm{n}}, 0.50 \mathrm{wt} \%$ by $\left[\mathrm{Ru}_{2}(\mathrm{SCA})_{2} \mathrm{Cl}\right]_{\mathrm{n}} \quad 0.73 \mathrm{wt} \%$ by $\left[\mathrm{Ru}_{2}(\mathrm{MCA})_{2} \mathrm{Cl}\right]_{\mathrm{n}}, \quad 0.54 \mathrm{wt} \%$ by $\left[\mathrm{Ru}_{2}(\mathrm{FMA})_{2} \mathrm{Cl}\right]_{\mathrm{n}}$, respectively. $\left[\mathrm{Ru}_{2}(\mathrm{MCA})_{2} \mathrm{Cl}\right]_{\mathrm{n}}$ having the highest surface area shows high $\mathrm{H}_{2}$ gas occupied performance. $\left[\mathrm{Ru}_{2}(\mathrm{FMA})_{2} \mathrm{Cl}\right]_{\mathrm{n}}$ and $\left[\mathrm{Ru}_{2}(\mathrm{SCA})_{2} \mathrm{Cl}\right]_{\mathrm{n}}$ are almost same. $\left[\mathrm{Ru}_{2}(\mathrm{TP})_{2} \mathrm{Cl}\right]_{\mathrm{n}}$ exhibits similar gas adsorption amount compared with $\left[\mathrm{Ru}_{2}(\mathrm{MCA})_{2} \mathrm{Cl}\right]_{\mathrm{n}}$, although surface area is lower than that of $\left[\mathrm{Ru}_{2}(\mathrm{MCA})_{2} \mathrm{Cl}\right]_{\mathrm{n}}$ and near to $\left[\mathrm{Ru}_{2}(\mathrm{SCA})_{2} \mathrm{Cl}\right]_{\mathrm{n}}$ From these results, we assumed that benzene ring is effective for $\mathrm{H}_{2}$ gas adsorption.

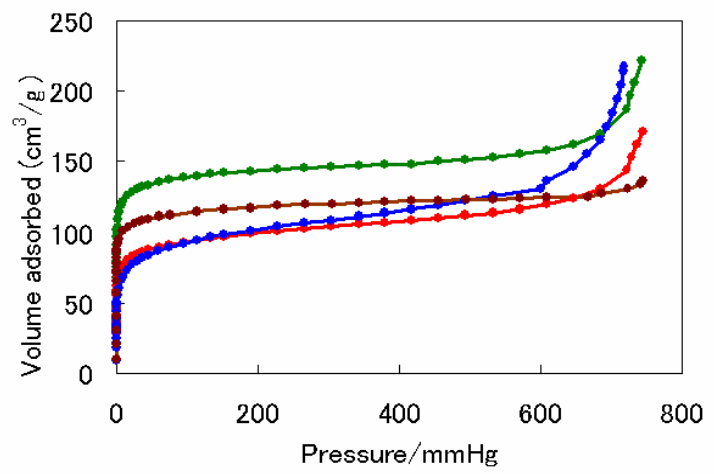

Figure $2 \mathrm{~N}_{2}$ gas isotherm plot of $\mathrm{Ru}^{\mathrm{II} / \mathrm{III}}{ }_{2}$ motifs (O $\left[\mathrm{Ru}_{2}(\mathrm{TP})_{2} \mathrm{Cl}\right]_{\mathrm{n}}, \quad\left[\mathrm{Ru}_{2}(\mathrm{FMA})_{2} \mathrm{Cl}\right]_{\mathrm{n}}, \bigcirc\left[\mathrm{Ru}_{2}(\mathrm{MCA})_{2} \mathrm{Cl}\right]_{\mathrm{n}}$, $\left.\left[\mathrm{Ru}_{2}(\mathrm{SCA})_{2} \mathrm{Cl}\right]_{\mathrm{n}}\right)$

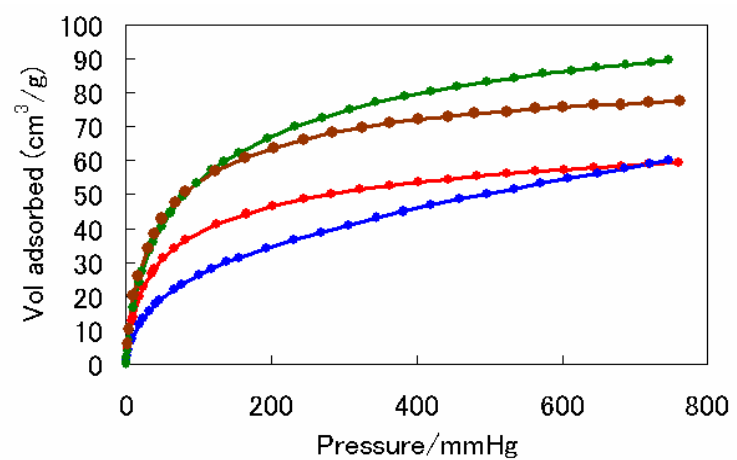

Figure $3 \mathrm{H}_{2}$ gas isotherm plot of $\mathrm{Ru}^{\mathrm{II} / \mathrm{III}}{ }_{2}$ motifs (O $\left[\mathrm{Ru}_{2}(\mathrm{TP})_{2} \mathrm{Cl}\right]_{\mathrm{n}}, \quad\left[\mathrm{Ru}_{2}(\mathrm{FMA})_{2} \mathrm{Cl}\right]_{\mathrm{n}}, \quad\left[\mathrm{Ru}_{2}(\mathrm{MCA})_{2} \mathrm{Cl}\right]_{\mathrm{n}}$, $\left.\left[\mathrm{Ru}_{2}(\mathrm{SCA})_{2} \mathrm{Cl}\right]_{\mathrm{n}}\right)$

\section{Conclusion}

We demonstrated that gas adsorption property of four type $\mathrm{Ru}^{\mathrm{II} / \mathrm{III}} 2$ microporous ruthenium coordination polymers constructed from $\mathrm{Ru}^{\mathrm{II} / \mathrm{III}} 2$ paddle wheel motifs as building blocks and four dicarboxylic acid ligand as building units. From the $\mathrm{N}_{2}$ gas adsorption measurement, the surface area of $\mathrm{Ru}^{\mathrm{II} / I I I}$ ${ }_{2}$ motifs is good agreement with the order of the length of ligand. The amount of $\mathrm{H}_{2}$ gas adsorbed is non-relationship with surface area, and $\left[\mathrm{Ru}_{2}(\mathrm{tp})_{2} \mathrm{Cl}\right]_{\mathrm{n}}$ shows high affinity concerning $\mathrm{H}_{2}$ adsorption.

\section{Acknowledgement}

This work was supported by a Grant-in-Aid for Specially Promoted Research (No. 19350077) and the High-tech Research Center Project from the Ministry of Education, Culture, Sports, Science and Technology of Japan.

\section{References}

[1] W. Mori, F. Inoue, K. Yoshida, H. Nakayama, 
S.Takamizawa, Chem. Lett,. 1998, 171219.

[2] H. Furukawa, M. A. Miller, and O. M. Yaghi, J. Mater. Chem., 2007, 17, 3197.

[3] S. Takamizawa, E. Nakata, T. Akatsuka, C. K. Terajima, R. Miyake, J. Am. Chem. Soc., 2008, 130,17882 .

[4]S.Kitagawa, R. Kitaura, S. Noro, Angew. Chem., Int. Ed., 2004, 43, 2334.

[5] T.Ohmura, W.Mori, H. Hiraga, M. Ono, Y. Nishimoto, Chem. Lett., 2003, 5. 32

[6] S.Naito, T. Tanibe, E. Saito, T. Miyao, W. Mori, Chme. Lett. , 2001, 1178.

[7] W. Mori, T. Sato, T. Ohmura, C. N. Kato, T. Takei, J. Solid State Chem., 2005, 178, 2555.

[8] C. N. Kato, M. Ono, T. Hino, T. Ohmura, W. Mori, Catal. Commun., 2006, 7, 673.

[9] Y.Kataoka, K. Sato, Y. Miyazaki, K. Masuda, H.Tanaka, S. Naito, W. Mori, Energy.Envirn. Sci. 2009, 2, 397

[10] Y. Kataoka, K. Sato, Y. Miyazaki, Y. Suzuki, H. Tanaka, Y. Kitagawa T. Kawakami, M. Okumura, W. Mori. Chem. Lett., 2010, 39, 358.

[11] S.Takamizawa, K. Yamaguchi, W. Mori, Inorg. Chem. Commun., 1998, 1. 177.

[12] G. Ribeiro, F. M. Vichi, D. D. O. Silva, J. Mol. Struct., 2008, 890, 209.

[13] B. Chen, S. Ma, F. Zapata, F. R. Fronczek, E. B.

Lobkovsky, H. Zhou. Inorg. Chem., 2007, 4, 46.

[14] G. Harvath, K. Kawazoe, J. chem. Eng. Japan, 1983, 16, 470.

(Received December 31, 2009; Accepted May 24, 2010) 